\title{
Developmental undernutrition, offspring obesity and type 2 diabetes
}

\author{
Aryeh D. Stein ${ }^{1} \cdot$ Okezi E. Obrutu ${ }^{1} \cdot$ Rishikesh V. Behere ${ }^{2} \cdot$ Chittaranjan S. Yajnik $^{2}$
}

Received: 8 April 2019 / Accepted: 21 May 2019 / Published online: 27 August 2019

(C) Springer-Verlag GmbH Germany, part of Springer Nature 2019

\begin{abstract}
The Developmental Origins of Health and Disease ( $\mathrm{DOHaD})$ paradigm posits that a mismatch between circumstances at or around conception and in later life leads to metabolic dysregulation and the development of obesity and diabetes. In this review we highlight three strands of evidence: prospective studies of patterns of growth from birth to adulthood, historical studies of exposure to famine at defined points during gestation and early life, and nutrition intervention studies. We conclude that, while much is still unknown, it is becoming clearer that the combination of early-life undernutrition and later development of obesity is associated with increased risk of diabetes. There is a need to support public health programmes aimed at intergenerational (primordial) prevention of diabetes and other non-communicable disease.
\end{abstract}

Keywords Life course development $\cdot$ Obesity $\cdot$ Review $\cdot$ Type 2 diabetes $\cdot$ Undernutrition

\section{Abbreviation \\ GDM Gestational diabetes mellitus}

\section{Introduction}

The Developmental Origins of Health and Disease (DOHaD) paradigm posits that exogenous exposure to environmental factors at critical stages of fetal and postnatal development influence organ size and function — changes that are intended to enhance survival probability in the short- to medium term [1]. The mismatch hypothesis further posits that, when such a programmed system encounters an environment that is not what was predicted, later outcomes will be sub-optimal [2]. This hypothesis has been advanced to explain the rapid increase in prevalence of cardiometabolic disease, including type 2 diabetes mellitus, in societies undergoing rapid economic and nutritional transitions and among migrants from low- and middle-income to high-income settings. The changes in dietary intake and obesity prevalence, collectively

Chittaranjan S. Yajnik

csyajnik@gmail.com

1 Hubert Department of Global Health, Rollins School of Public Health, Emory University, Atlanta, GA, USA

2 Diabetes Unit, King Edward Memorial Hospital Research Centre, Rasta Peth, Pune 411011, India known as the nutrition transition, have been extensively documented [3].

It is of interest in public health to establish the magnitude of the risk of cardiometabolic disease that individuals exposed to mismatch carry with them, in order to develop effective intervention strategies to mitigate later adverse outcomes. We therefore discuss the role of undernutrition on the incidence of obesity and type 2 diabetes. We summarise three strands of evidence that address, each in their own way, the challenges inherent in the study of the long-term consequences of nutritional exposure in fetal life and early childhood.

\section{Patterns of childhood growth}

Size at birth has often been associated with adult outcomes [4]. The Consortium on Health-Orientated Research in Transitioning Societies (COHORTS) is a collaboration among birth cohort studies in five low- and middle-income countries [5]. Using an approach that disentangles the usual high correlation among measures of size during childhood through the use of 'conditional growth' measures - the residuals from regressions of length at one point on all measures of length at prior points - they have shown that birthweight is inversely associated with prevalent dysglycaemia [6], and that increased linear growth in early childhood is associated with increased adiposity in adult life but not with risk of dysglycaemia. On the other hand, increased weight for height at any age increased the likelihood of both obesity and dysglycaemia. 
India is rapidly moving towards becoming the world's diabetes capital. Indians with diabetes tend to be younger, shorter and have lower BMI compared with Europeans with diabetes, although they have higher adiposity [7]. Several observational studies provide evidence concerning the pattern of growth and subsequent disease burden.

The New Delhi Birth Cohort Study was initiated in 19691972, when married women of reproductive age were enrolled. Pregnancies were identified through ongoing surveillance and the children were followed from birth. At age 30 years, the cohort was re-contacted and screened for diabetes. The combined prevalence of impaired fasting glucose and of diabetes was $15.2 \%$. Those with diabetes had a distinct pattern of growth - they were initially thinner than the rest of the cohort, but by age 10 years had 'caught up' in terms of BMI (although they were generally not obese), and from that point on had higher mean BMI than the cohort members without diabetes [8]. Similar associations have been reported in a cohort from Helsinki, Finland, lending credence to these findings [9].

In the Pune Children's Study, a hospital-based study of 4year-old children of mean birthweight $2.7 \mathrm{~kg}$, lower birthweight was associated with higher glucose and higher insulin concentrations during an oral glucose tolerance test [10]. At 8 years of age, children who were born small but grew big had the highest levels of adiposity, insulin resistance, blood pressure and lipids, all risk factors for diabetes and cardiovascular disease [11].

Among adults born in a hospital in Mysore, smaller size at birth was associated with higher risk of cardiovascular disease, but the risk of diabetes was associated with higher ponderal index (a measure of the relationship between weight and height, used as an alternative to BMI) at birth and with larger pelvic size of the mothers [12]. These findings raise the possibility that this association could have been driven by maternal hyperglycaemia in pregnancy.

The Pune Maternal Nutrition Study (PMNS) was established in an impoverished, drought-prone area, which has subsequently undergone rapid socioeconomic transition, to study the association between maternal nutrition, fetal growth and long-term cardiometabolic risk. At recruitment, women had a mean age of 21 years, a mean height of $1.52 \mathrm{~m}$, and a mean BMI of $18.1 \mathrm{~kg} / \mathrm{m}^{2}$. The women were physically active but reportedly ate less than 2000 calories and $45 \mathrm{~g}$ protein per day [13]. Deficiencies of iron, vitamin $\mathrm{B}_{12}$ and vitamin D were common, but folate status was good. Newborn babies were on average $2.7 \mathrm{~kg}$ and thin (ponderal index $24.5 \mathrm{~kg} / \mathrm{m}^{3}$ ) in the Pune cohort. In comparison with babies in the Southampton cohort (mean birthweight $3.5 \mathrm{~kg}$, mean ponderal index $27.5 \mathrm{~kg} / \mathrm{m}^{3}$ ), Indian babies had relatively preserved subscapular skinfold thickness [14] and higher subcutaneous and visceral abdominal fat on MRI [15]. The cord blood of Indian babies showed higher concentrations of leptin and lower concentrations of adiponectin [16]. This 'thin-fat' neonatal phenotype is also seen in multigenerationally migrant Indians in Surinam [17], in Pakistani children in the Born in Bradford cohort [18] and in migrant Indians in Canada [19]. Small parental size, lower maternal intake of micronutrient-rich foods (green leafy vegetables, milk and fruit) [13], lower circulating nutrient concentrations (vitamin $\mathrm{B}_{12}$, folate, vitamin $\mathrm{D}$ ) and disturbed one-carbon metabolism (higher homocysteine concentrations) were associated with poor fetal growth [20], as was excessive physical activity of the mother [21]. Follow-up of these babies revealed that low maternal circulating vitamin $\mathrm{B}_{12}$ and high folate concentrations in pregnancy were associated with higher levels of adiposity and insulin resistance in the children. At age 18 years, cohort members were $5 \mathrm{~cm}$ taller than their parents; $18 \%$ of female and $35 \%$ of male participants had prediabetes (impaired glucose tolerance and/or impaired fasting glucose) despite an average BMI of only $19 \mathrm{~kg} / \mathrm{m}^{2}$ (Yajnik CS, et al, unpublished results). The prevalence of gestational diabetes mellitus (GDM) in the daughters (F1) was higher than in their mothers (F0) [22].

The finding of higher ponderal index at birth in adults with diabetes in the Mysore cohort led to the establishment of the Parthenon Cohort to study maternal diabetes and its effect on fetal growth and future risk of diabetes. In this study, children born to mothers with GDM were heavier and had higher adiposity at birth [23]. It is important to keep in mind that the average birthweight of these babies was still only $3.3 \mathrm{~kg}$. Adiposity among these children (especially the girls) increased and they became progressively more insulin resistant and hyperglycaemic during childhood and early adolescence compared with children born to mothers without GDM or children born to fathers with diabetes.

\section{Famine exposure during gestation and early childhood}

A major challenge in interpreting studies, such as those summarised in the previous section, that report an association between size at key periods in childhood and disease outcomes in later life is that the role of nutrition is not always clear [24]. One approach to disentangling these factors has been the study of women who were exposed to the nutritional and related stresses of famine. The long-term consequences of famine exposure have been explored most extensively using data from the Dutch Hunger Winter of 1944-1945 [25].

The Dutch famine resulted from a combination of an exceptionally harsh winter, bad crops, 4 years of brutal war and the embargo imposed by the Nazis on the western Netherlands between 1944 and 1945 [26]. In a historical cohort study of 300,000 Dutch 19 year olds examined at military induction it 
was observed that famine exposure during the first half of pregnancy was associated with significantly higher rates of obesity, while exposure during the second half of pregnancy and the first few months of postnatal life was associated with significantly lower obesity rates [27]. In a subsequent study carried out among participants born in a university hospital in Amsterdam, the BMI of 50 year old women exposed to famine in early gestation was $7.4 \%$ higher than that of nonexposed women [28]. This association was not observed in women exposed in mid- and late gestation or in men. A similar association with BMI and hip and waist circumferences in women was reported in an independent sample of participants born in different institutions in the famine-exposed region of the Netherlands [29]. Previous studies have shown measures of waist size to be more representative of visceral obesity and risk for obesity-related illnesses than BMI [30]. Additional famines that have been considered occurred in Ukraine [31], Leningrad [32], China [33], Biafra [34] and Bangladesh [35].

The Great Ukrainian Famine of 1932-1933 was a result of the Soviet Union's forced collectivisation of agriculture in the early 1930s. A retrospective cohort study of participants recruited from the Ukraine national register who lived in eastern and western Ukraine during the famine was conducted [31]. All patients with type 2 diabetes diagnosed at age 40 years or older in the Ukraine national diabetes register 2000-2008 were enrolled as the cases and individuals born between 1930 and 1938 from the 2001 Ukraine national census were used as the reference population. The findings showed increased odds of developing type 2 diabetes in adulthood among individuals born during the famine in the areas with severe to extreme famine. It also noted a dose-response relationship between the severity of famine exposure and the likelihood of later type 2 diabetes.

The Chinese famine of 1958-1961 was due to a combination of poor economic policies and drought [33]. The several studies that have been published on the effects of the Chinese famine used cross-sectional or cohort study designs and recruited participants from households, existing cohort studies or hospital databases. The range of outcome measures used for diabetes by the different studies include fasting plasma glucose $\geq 7.0 \mathrm{mmol} / 1,2 \mathrm{~h}$ post-OGTT glucose $\geq 11.1 \mathrm{mmol} / \mathrm{l}$, $\mathrm{HbA}_{1 \mathrm{c}} \geq 6.5 \%$, self-reported physician-diagnosed diabetes and use of glucose-lowering medications. There was a consistent finding of an association between famine exposure in early life and hyperglycaemia/diabetes in adulthood. There were slight variations in the pattern of observations across different studies. One study reported this association only in areas of severe famine compared with less severe and unexposed areas [36], another reported increased risk among male participants exposed in utero and female participants exposed in early childhood compared with other participants [37]. Yet another study reported this association for prenatal exposure alone (OR 1.93 for hyperglycaemia, 1.75 for diabetes) [38], and another reported a $38 \%$ higher risk for those exposed to severe famine [39]. Several studies have analysed the association with obesity (BMI $\geq 28 \mathrm{~kg} / \mathrm{m}^{2}$, which is the threshold generally used in Chinese populations). One reported 38.4\% higher odds of obesity among early-life famine-exposed participants [40], while another study found this association only in women [41].

The Biafran famine was associated with the war that followed the declaration of independence of the Republic of Biafra from Nigeria. A cohort study enrolled participants born between 2 years before and 3 years after the war from marketplaces in Enugu [34]. Increased odds of both impaired glucose tolerance and diabetes among men and women exposed to fetal/infant famine were observed in comparison with individuals born after the famine. Early childhood exposure was not associated with diabetes. Similarly, the odds of being overweight were 1.41 times higher among participants exposed to fetal-infant famine in comparison with individuals born after the famine. Stratified analysis showed this effect to be confined to women.

The Bangladeshi famine of 1974 resulted from a severe monsoon that destroyed most of the annual rice crop, in addition to inadequacies in the food distribution system, unemployment and lower purchasing power [35]. Famine exposure was associated with increased prevalence of hyperglycaemia and elevated fasting glucose among prenatally exposed individuals who were underweight at the time of examination and among postnatally exposed individuals. Postnatal exposure was associated with a higher prevalence of overweight and obesity compared with prenatal or no exposure. It was twice as common for young adults to be overweight or obese if they had been exposed to famine during postnatal life compared with those exposed in utero or unexposed.

Collectively, the famine studies paint a somewhat inconsistent picture of increased risk of obesity and diabetes in later life following exposure to famine during gestation. However, each of the studies has methodological limitations that reduce confidence in the causality of any associations. One concern is that the mismatch hypothesis requires that there be ample nutrition in the period following the famine, as evidenced by increases in obesity, to trigger the metabolic dysregulation. Additional limitations include inadequate control for age and cohort effects, as well as selection bias resulting from case registration and selection of the control population [42].

\section{Intervention studies of nutrition supplementation in pregnancy and childhood}

Direct tests of the role of nutrition in the aetiology of adult obesity and diabetes are rare. The Institute of Nutrition of Central America and Panama (INCAP) launched a nutrition supplementation trial in four villages in the eastern highlands 
of Guatemala [43]. The objective of the trial was to test the hypothesis that improved nutrition would enhance linear growth and cognitive development. The four villages were randomised within pairs matched on size to receive either atole, a gruel made of Incaparina (a nutritionally balanced complementary food), dried skimmed milk and sugar, or fresco, a protein-free drink in which all the energy came from sugar, and which had a lower energy value. The beverages were provided twice daily at a central feeding station in each village and consumption was recorded for pregnant and lactating women and children under 7 years. Children aged 7 years or younger at study launch and those born during the study intervention period were enrolled $(n=2392)$ and have been followed. At mean age 45 years, a comprehensive clinical assessment was conducted, including anthropometry and an oral glucose tolerance test. The population is characterised by very high levels of overweight and obesity, and the prevalence of diabetes was determined to be $9 \%$ in male and $17 \%$ in female participants. The researchers used a difference-indifference approach to estimate the effect of exposure to improved nutrition during the 'first 1000 days' - the period from conception to a child's second birthday. The authors found that the odds for obesity (BMI $>30 \mathrm{~kg} / \mathrm{m}^{2}$ ) were higher (OR $1.94,95 \%$ CI 1.11, 3.40) and the odds for diabetes lower (OR $0.46,95 \%$ CI $0.21,0.97)$ for individuals exposed to atole in the first 1000 days compared with those exposed to atole at other ages or to fresco [44]. These estimates were robust to adjustment for several covariates, and the estimate for diabetes was unchanged with further control for BMI.

Two nutritional intervention trials are underway in India. The first, the Mumbai Maternal Nutrition Project (MMNP) provided a samosa stuffed with a powder of green leafy vegetables, fruit and milk to women from Mumbai slums, starting many months before pregnancy and continuing until delivery. In MMNP the intervention group had a $50 \mathrm{~g}$ increase in birthweight [45], and a reduction in incidence of GDM [46]. The children are being followed for size, body composition and cardiometabolic risk; no results are yet available. In the second trial, Pune Rural Intervention in Young Adults (PRIYA), adolescents are supplemented with an RDA dose of vitamin $\mathrm{B}_{12}$, with or without multi-micronutrients, from before marriage until delivery of their first child [47]. The study is ongoing.

\section{Mechanisms and potential interventions}

Epigenetics is a likely mechanism for the early-life programming due to maternal undernutrition. Differential DNA methylation has been shown to be related to periconceptional exposure to the Dutch famine [48] and may be influenced by maternal one-carbon metabolism [49]. Indian mothers are at high risk of such disturbance owing to dietary deficiencies of vitamin $\mathrm{B}_{12}$ and other methyl donor nutrients because of predominantly vegetarian habits.

There are major challenges to disentangling the specific role of undernutrition from other exposures that occur among children. The birth cohorts from India have made important contributions. These observations suggest two important risk factors for obesity and non-communicable disease in later life. The first is that maternal undernutrition during periconception and pregnancy could manifest as a thin-fat phenotype in the baby, and that if such babies grow heavier in childhood they are at higher risk of adiposity, diabetes and cardiovascular disease. Second, urbanisation and overnutrition can give rise to adiposity and glucose intolerance at a young age, and in girls this may manifest as gestational hyperglycaemia, which propagates the cycle of obesity and diabetes to the next generation. In rapidly developing countries such as India, the 'double burden of malnutrition' (a substantial prevalence of undernutrition, particularly in newborns, infants, children and young adults of reproductive age, alongside a growing prevalence of obesity in adults) challenges and overburdens public health systems because the approach for the two is contradictory. The original finding that small size at birth is associated with increased risk of diabetes and other non-communicable diseases in later life [4] indeed suggests that lifestyle modification in adults will provide a temporary relief, but that longterm benefit will come only from improving early-life growth and development.

The only study, from Guatemala, in which an intervention designed to improve linear growth has been examined with respect to diabetes prevalence, found that diabetes prevalence was lower in those exposed to improved nutrition during the first 1000 days [44]. This suggests that the cycle of risk for development of diabetes consequent to early-life undernutrition can be broken by improving nutrition during pregnancy and in early childhood. There have been major improvements in the nutritional status of children in low- and middle-income countries [50], but there is still more to be done. However, as the prevalence of stunting decreases, there is concern that children are increasingly becoming overweight. Further study will be needed to determine the long-term consequences of this, together with the tracking of obesity over the life course; there is also a need to support public health programmes aimed at intergenerational (primordial) prevention of diabetes and other non-communicable diseases.

Acknowledgements We thank the participants in our studies and our collaborators.

Funding CSY reports funding from the Department of Biotechnology, Govt of India, New Delhi: BT/PR12629/MED/97/364/2016; the Indian Council of Medical Research \& Medical Research Council, UK joint grant under an Indo-UK call: ICMR-MRC- (58/1/8/MRC-ICMR/2009/ NCD-II) MRC- (MR/J000094/1); The Wellcome Trust: 034384/Z/91/Z, 038128/Z/93. 
Duality of interest The authors declare that there is no duality of interest associated with this manuscript.

Contribution statement All authors were responsible for drafting the article and revising it critically for important intellectual content. All authors approved submission.

\section{References}

1. Hanson MA, Gluckman PD (2014) Early developmental conditioning of later health and disease: physiology or pathophysiology? Physiol Rev 94(4):1027-1076. https://doi.org/10.1152/physrev. 00029.2013

2. Gluckman P, Hanson M (2006) Mismatch: why our world no longer fits our bodies. Oxford University Press, Oxford

3. Willett W, Rockström J, Loken B et al (2019) Food in the Anthropocene: the EAT-Lancet Commission on healthy diets from sustainable food systems. Lancet 393(10170):447-492. https://doi. org/10.1016/S0140-6736(18)31788-4

4. Barker DJP (1998) Mothers, babies and health in later life, 2nd edn. Churchill Livingstone, Edinburgh

5. Richter L, Victora C, Hallal P et al (2012) Cohort profile: the Consortium of Health Orientated Research in Transitioning Societies (COHORTS). Int J Epidemiol 41:627-633

6. Adair LA, Fall CHD, Osmond CO et al (2013) Associations of linear growth and relative weight gain during early life with adult health and human capital in countries of low and middle income: findings from five birth cohort studies. Lancet. 382(9891):525-534. https://doi.org/10.1016/S0140-6736(13)60103-8

7. Yajnik C (2001) The insulin resistance epidemic in India: fetal origins, later lifestyle, or both? Nutr Rev 59(1):1-9

8. Bhargava SK, Sachdev HS, Fall CH et al (2004) Relation of serial changes in childhood body-mass index to impaired glucose tolerance in young adulthood. N Engl J Med 350(9):865-875. https:// doi.org/10.1056/NEJMoa035698

9. Eriksson JG, Osmond C, Kajantie E, Forsén TJ, Barker DJ (2006) Patterns of growth among children who later develop type 2 diabetes or its risk factors. Diabetologia. 49(12):2853-2858. https://doi. org/10.1007/s00125-006-0459-1

10. Yajnik CS, Fall CH, Vaidya U et al (1995) Fetal growth and glucose and insulin metabolism in four-year-old Indian children. Diabet Med 12(4):330-336. https://doi.org/10.1111/j.1464-5491.1995. tb00487.x

11. Bavdekar A, Yajnik CS, Fall CH et al (1999) Insulin resistance syndrome in 8-year-old Indian children: small at birth, big at 8 years, or both? Diabetes. 48(12):2422-2429. https://doi.org/10. 2337/diabetes.48.12.2422

12. Fall CH, Stein CE, Kumaran K et al (1998) Size at birth, maternal weight, and type 2 diabetes in South India. Diabet Med 15(3):220 227. https://doi.org/10.1002/(SICI)1096-9136(199803)15:3<220:: AID-DIA544>3.0.CO;2-O

13. Rao S, Yajnik CS, Kanade A et al (2001) Intake of micronutrientrich foods in rural Indian mothers is associated with the size of their babies at birth: Pune Maternal Nutrition Study. J Nutr 131(4):12171224. https://doi.org/10.1093/jn/131.4.1217

14. Yajnik CS, Fall CH, Coyaji KJ et al (2003) Neonatal anthropometry: the thin-fat Indian baby. The Pune Maternal Nutrition Study. Int J Obes Relat Metab Disord 27(2):173-180. https://doi.org/10.1038/ sj.ijo. 802219

15. Modi N, Thomas EL, Uthaya SN, Umranikar S, Bell JD, Yajnik C (2009) Whole body magnetic resonance imaging of healthy newborn infants demonstrates increased central adiposity in Asian Indians. Pediatr Res 65(5):584-587. https://doi.org/10.1203/PDR. 0b013e31819d98be

16. Yajnik CS, Lubree HG, Rege SS et al (2002) Adiposity and hyperinsulinemia in Indians are present at birth. J Clin Endocrinol Metab 87(12):5575-5580. https://doi.org/10.1210/jc.2002-020434

17. Van Steijn L, Karamali NS, Kanhai HH et al (2009) Neonatal anthropometry: thin-fat phenotype in fourth to fifth generation South Asian neonates in Surinam. Int J Obes 33(11):1326-1329. https:// doi.org/10.1038/ijo.2009.154

18. West J, Wright J, Fairley L, Sattar N, Whincup P, Lawlor DA (2013) Do ethnic differences in cord blood leptin levels differ by birthweight category? Findings from the Born in Bradford cohort study. Int J Epidemiol 43(1):249-254

19. Anand SS, Gupta MK, Schulze KM et al (2016) What accounts for ethnic differences in newborn skinfold thickness comparing South Asians and White Caucasians? Findings from the START and FAMILY Birth Cohorts. Int J Obes 40(2):239-244. https://doi.org/ 10.1038/ijo.2015.171

20. Yajnik CS, Chandak GR, Joglekar C et al (2014) Maternal homocysteine in pregnancy and offspring birthweight: epidemiological associations and Mendelian randomization analysis. Int $\mathbf{J}$ Epidemiol 43(5):1487-1497. https://doi.org/10.1093/ije/dyu132

21. Rao SA, Kanade BM, Margetts CS et al (2003) Maternal activity in relation to birth size in rural India. The Pune Maternal Nutrition Study. Eur J Clin Nutr 57(4):531-542. https://doi.org/10.1038/sj. ejcn. 1601582

22. Memane NS, Bhat D, Raut DA et al (2018) Pregnancy glycemia reflects life course glycemia of the mother. Diabetes 67(Suppl 1). https://doi.org/10.2337/db18-118-OR

23. Hill JC, Krishnaveni GV, Annamma I, Leary SD, Fall CH (2005) Glucose tolerance in pregnancy in South India: relationships to neonatal anthropometry. Acta Obstet Gynecol Scand 84(2):159165. https://doi.org/10.1111/j.0001-6349.2005.00670.x

24. Leroy JL, Frongillo EA (2019) Perspective: what does stunting really mean? A critical review of the evidence. Adv Nutr 10(2): 196-204. https://doi.org/10.1093/advances/nmy101

25. Lumey LH, Stein AD, Susser ES (2011) Prenatal famine and adult physical and mental health. Annu Rev Public Health 32(1):237262. https://doi.org/10.1146/annurev-publhealth-031210-101230

26. Lumey LH, Stein AD, Kahn HS et al (2007) Cohort profile: the Dutch Hunger Winter Families Study. Int J Epidemiol 36(6):11961204. https://doi.org/10.1093/ije/dym126

27. Ravelli GP, Stein ZA, Susser MW (1976) Obesity in young men after famine exposure in utero and early infancy. N Engl J Med 295(7):349-353. https://doi.org/10.1056/nejm197608122950701

28. Ravelli AC, van Der Meulen JH, Osmond C, Barker DJ, Bleker OP (1999) Obesity at the age of $50 \mathrm{y}$ in men and women exposed to famine prenatally. Am J Clin Nutr 70(5):811-816. https://doi.org/ 10.1093/ajen/70.5.811

29. Stein AD, Kahn HS, Rundle A, Zybert PA, van der Pal-de Bruin K, Lumey LH (2007) Anthropometric measures in middle age after exposure to famine during gestation: evidence from the Dutch Famine. Am J Clin Nutr 85(3):869-876. https://doi.org/10.1093/ ajen/85.3.869

30. West-Eberhard MJ (2019) Nutrition, the visceral immune system, and the evolutionary origins of pathogenic obesity. PNAS 116(3): 723-731. https://doi.org/10.1073/pnas. 1809046116

31. Lumey LH, Khalangot MD, Vaiserman AM (2015) Association between type 2 diabetes and prenatal exposure to the Ukraine famine of 1932-33: a retrospective cohort study. Lancet Diabetes Endocrinol 3(10):787-794. https://doi.org/10.1016/s22138587(15)00279-x

32. Stanner SA, Bulmer K, Andrès C et al (1997) Does malnutrition in utero determine diabetes and coronary heart disease in adulthood? Results from the Leningrad siege study, a cross sectional study. 
BMJ 315(7119):1342-1348. https://doi.org/10.1136/bmj.315.7119. 1342

33. Li C, Lumey LH (2017) Exposure to the Chinese famine of 195961 in early life and long-term health conditions: a systematic review and meta-analysis. Int J Epidemiol 46(4):1157-1170. https://doi. org/10.1093/ije/dyx013

34. Hult M, Tornhammar P, Ueda P et al (2010) Hypertension, diabetes and overweight: looming legacies of the Biafran famine. PLoS One 5(10):e13582. https://doi.org/10.1371/journal.pone.0013582

35. Finer S, Iqbal MS, Lowe R et al (2016) Is famine exposure during developmental life in rural Bangladesh associated with a metabolic and epigenetic signature in young adulthood? A historical cohort study. BMJ Open 6(11):e011768. https://doi.org/10.1136/bmjopen2016-011768

36. Li J, Liu S, Li S et al (2017) Prenatal exposure to famine and the development of hyperglycemia and type 2 diabetes in adulthood across consecutive generations: a population-based cohort study of families in Suihua, China. Am J Clin Nutr 105(1):221-227. https://doi.org/10.3945/ajen.116.138792

37. Wang J, Li Y, Han X et al (2016) Exposure to the Chinese famine in childhood increases type 2 diabetes risk in adults. J Nutr 146(11): 2289-2295. https://doi.org/10.3945/jn.116.234575

38. Chen JP, Peng B, Tang L et al (2016) Fetal and infant exposure to the Chinese famine increases the risk of fatty liver disease in Chongqing, China. J Gastroenterol Hepatol 31(1):200-205. https://doi.org/10.1111/jgh.13044

39. Yang Z, Zhao W, Zhang $X$ et al (2008) Impact of famine during pregnancy and infancy on health in adulthood. Obes Rev 9(Suppl 1):95-99. https://doi.org/10.1111/j.1467-789X.2007.00447.x

40. Wang N, Wang X, Han B et al (2015) Is exposure to famine in childhood and economic development in adulthood associated with diabetes? J Clin Endocrinol Metab 100(12):4514-4523. https://doi. org/10.1210/jc.2015-2750

41. Li J, Liu S, Li S et al (2017) Prenatal exposure to famine and the development of hyperglycemia and type 2 diabetes in adulthood across consecutive generations: a population-based cohort study of families in Suihua, China. Am J Clin Nutr 105(1):221-227. https://doi.org/10.3945/ajcn.116.138792

42. Li C, Lumey LH (2017) Studies into severe famine in early life and diabetes in adulthood: the need to control for differences in participant age and location. Diabetologia. 60(7):1359-1360. https://doi. org/10.1007/s00125-017-4300-9

43. Stein AD, Hoddinott J, Melgar P, Martorell R (2008) Cohort profile: the Institute of Nutrition of Central America and Panama (INCAP)
Nutrition Trial Cohort Study. Int J Epidemiol 37(4):716-720. https://doi.org/10.1093/ije/dyn028

44. Ford ND, Behrman JR, Hoddinott JF et al (2018) Exposure to improved nutrition from conception to age two years and adult cardiometabolic disease risk: a modelling study. Lancet Global Health 6(8):e875-e884. https://doi.org/10.1016/S2214-109X(18) 30231-6

45. Potdar RD, Sahariah SA, Gandhi M et al (2014) Improving women's diet quality preconceptionally and during gestation: effects on birth weight and prevalence of low birth weight - a randomized controlled efficacy trial in India (Mumbai Maternal Nutrition Project). Am J Clin Nutr 100(5):1257-1268. https://doi. org/10.3945/ajcn.114.084921

46. Sahariah SA, Potdar RD, Gandhi M et al (2016) A daily snack containing leafy green vegetables, fruit, and milk before and during pregnancy prevents gestational diabetes in a randomized, controlled trial in Mumbai, India. J Nutr 146(7):1453S-1460S. https://doi.org/ 10.3945/jn.115.223461

47. Kumaran K, Yajnik P, Lubree H et al (2017) The Pune Rural Intervention in Young Adolescents (PRIYA) study: design and methods of a randomised controlled trial. BMC Nutrition 3(1):41. https://doi.org/10.1186/s40795-017-0143-5

48. Heijmans BT, Tobi EW, Stein AD et al (2008) Persistent epigenetic differences associated with prenatal exposure to famine in humans. Proc Natl Acad Sci 105(44):17046-17049. https://doi.org/10.1073/ pnas.0806560105

49. Steegers-Theunissen RP, Twigt J, Pestinger V, Sinclair KD (2013) The periconceptional period, reproduction and long-term health of offspring: the importance of one-carbon metabolism. Hum Reprod Update 19(6):640-655. https://doi.org/10.1093/humupd/dmt041

50. Black RE, Victora CG, Walker SP et al (2013) Maternal and child undernutrition and overweight in low-income and middle-income countries. Lancet 382(9890):427-451. https://doi.org/10.1016/ S0140-6736(13)60937-X

Publisher's note Springer Nature remains neutral with regard to jurisdictional claims in published maps and institutional affiliations. 